\title{
CARTOGRAFIAS E FILOSOFÍSICA: SENSIBILIZANDO UM CORPO FEMININO DEFICIENTE
}
CARTOGRAPHIES AND PHILOSOPHYSICS: SENSITIZING A DISABLED FEMALE BODY

\section{CARTOGRAFÍAS Y FILOSOFÍSICA: SENSIBILIZANDO UN CUERPO FEMENINO DEFICIENTE}

\author{
CUNHA, Claudia Madruga \\ cmadrugacunha@gmail.com \\ Universidade Federal do Paraná \\ http://orcid.org/0000-0002-2867-5566 \\ RODRIGUES, Michele Caroline da Silva \\ michelecaroline13@gmail.com \\ Universidade Federal do Paraná \\ http://orcid.org/0000-0001-9777-6304
}

RESUMO Este estudo traz reflexões a respeito de uma cartografia desenvolvida em torno do corpo feminino deficiente, permeada pelos conceitos da Filosofia da Diferença de Gilles Deleuze e Félix Guattari e pelas contribuições sobre dança de José Gil. Problematiza as normativas sociais e estéticas e a invisibilidade de expressão do corpo deficiente feminino, a partir de experimentações de Dança Contato Improvisação realizadas com meninas e mulheres matriculadas numa escola especial da APAE. Almejou-se proporcionar, no contato entre corpos, um processo de expressão das diferenças, explorando um corpo sensível, um corpo sem órgãos.

Palavras-chave: Corpo Feminino Deficiente. Dança. Deleuze.

ABSTRACT This essay brings reflections of a cartography developed around the Disabled Female Body, permeated by the concepts of the Philosophy of Difference of Gilles Deleuze and Félix Guattari and the contributions on dance of José Gil. It problematizes the social and aesthetic norms and the invisibility of expression of the female disabled body. It was hoped through the Contact Improvisation dance to ease, in the contact between bodies, a process of expression of differences, exploring a sensitive body, a body without organs, a(n) (other) body.

Keywords: Dance. Deleuze. Disabled Female Body.

RESUMEN: Este estúdio trae reflexiones de una cartografia desarrollada en torno al Cuerpo Femenino Deficiente, impregnado por los conceptos de la Filosofía de la Diferencia de Gilles Deleuze y Félix Guattari y las contribuiciones sobre danza de José Gil. Problematiza la invisibilidad de los afectos y el reconocimiento de sí del cuerpo deficiente femenino. Através de la danza Contacto Improvisación, se esperaba hacer flexible el contacto entre cuerpos, 
Atos de Pesquisa em Educação - ISSN 1809-0354

Blumenau, v.14, n.3, p.1069-1091, set./dez. 2019

DOI: http://dx.doi.org/10.7867/1809-0354.2019v14n3p1069-1091

um proceso de expresión de diferencias, explorando um cuerpo sensible, um cuerpo sin órganos, um cuerpo (otro).

Palavras clave: Cuerpo Femenino Deficiente. Danza. Deleuze.

\section{INTRODUÇÃO}

Artaud (1987, p.98) dizia que "todo verdadeiro sentimento é na verdade intraduzível. Expressá-lo é traí-lo. Mas traduzi-lo é dissimulá-lo. A expressão verdadeira esconde o que ela manifesta". Na obra O teatro e seu duplo, o dramaturgo manifestou os limites que o corpo possui para expressar os sentimentos, quando a tentativa da expressão se afigura como linguagem da representação que não traduz as forças que atravessam a matéria corpórea e sensível. Daniel Lins, fazendo um estudo sobre a obra de Artaud, perguntou: "Qual é a matéria que compõe o corpo sem órgãos ou o corpo superior ou o corpo duro de Artaud? O Corpo sem Órgãos, responde Deleuze, é feito de ossos e de sangue" (LINS, 1999, p.47). Todos possuem um corpo e com ele se percebem entre outros corpos, tecendo relações que envolvem zonas, intensidades, latitudes e longitudes.

O corpo sem órgãos, cuja sigla é $\mathrm{CsO}$, aparece como um conceito que Gilles Deleuze e Félix Guattari tomam de empréstimo de Antonin Artaud (1987) e desenvolvem em duas obras: O anti-Édipo (1966) e Mil platôs (1988). Ambas são posteriores ao livro-tese deleuziano Diferença e repetição, no qual o filósofo expõe sua crítica a uma imagem de pensamento fundada na metafísica que vem desde Platão e fundamenta o pensamento sobre a diferença descolado da ontologia tradicional. A intenção foi assegurar que o diferente possa ser pensado não como oposição e identidade, em si e de si, mas como algo sempre em movimento e no estado de um disforme por vir, sem imagem prévia.

As sensações, os sentidos e os desejos que atravessam nossos corpos estão sempre em movimento. Entretanto, pouco estimulados a dar atenção ao que é singular em nosso próprio corpo, vivemos a tendência de nos identificar e codificar em imagens de outros corpos, propalados e em ascensão no meio sociocultural em que vivemos. Ademais, sentidos, sensações e desejos ficam submetidos a uma ordem transcendental que vem da linguagem e nos é sutilmente incorporada. Se, por um lado, o investimento na tradição do pensamento mantém sentido, sensações e desejos sob controle ou aparentemente sob 
Atos de Pesquisa em Educação - ISSN 1809-0354

Blumenau, v.14, n.3, p.1069-1091, set./dez. 2019

DOI: http://dx.doi.org/10.7867/1809-0354.2019v14n3p1069-1091

controle, por outro - e aqui parafraseamos Lins -, o conceito de CsO demarca a ausência do desejo e, ao mesmo tempo, a presença estonteante do desejo em cada corpo vivo. $\mathrm{Na}$ análise que faz do legado artauniano, Lins (1999) chama atenção para uma proposta que desinveste na linguagem como algo fundado ou calcado na representação e sugere uma interpretação na qual o corpo serve a seus instintos e à crueldade que subjaz a essa submissão. Schöpke comenta

[...]que o CsO aparece em Artaud como uma declaração de guerra: guerra contra os órgãos, guerra contra o corpo ordenado, organizado, guerra, na verdade, contra o organismo em sua disposição e significância social. Trata-se de um "grito orgânico" do homem contra toda transcendência opressora. Trata-se de uma rebelião do próprio ser, que deseja a todo custo libertar a vida que se encontra aprisionada nele[....]. (SCHÖPKE, 2017, p.287).

Trazer à tona tais considerações é importante e oportuno para precipitar certo plano que organiza essa cartografia. O desenho que essa análise cartográfica deseja encaminhar brota de uma zona de tensão na qual o corpo feminino deficiente é como matéria organizada e invisibilizada no espaço escolar. Esse corpo não costuma ser aceito por sua produção de sentidos; aquilo que nele é espontâneo em geral é rejeitado, distanciado de uma percepção de si, silenciado em seus instintos afetivos.

\section{O PROCESSO CARTOGRÁFICO E PENSAR O SENSÍVEL}

A cartografia, por ser uma metodologia que permite que o processo se construa à medida que os acontecimentos ocorrem, favorece organizar uma proposta fundada na Filosofia da Diferença de Gilles Deleuze (1988). Atravessado pelo já citado conceito de CsO de Deleuze e Guattari (1966, 1996), esse processo potencializa o movimento e faz fluir afetos e percepções de si, numa direção tal que pode levar a uma outra imagem sensória desses corpos deficientes femininos.

A pesquisa teve origem na observação de um grupo de meninas e mulheres com deficiência intelectual ou física leve, com idade igual ou superior a 18 anos e matriculadas em uma sede da APAE de Curitiba, cujos corpos davam sinais de amadurecimento sexual em linguagem erótica e afetiva, na maioria das vezes linguagem sem interlocução. 


\section{Atos de Pesquisa em Educação - ISSN 1809-0354 \\ Blumenau, v.14, n.3, p.1069-1091, set./dez. 2019 \\ DOI: http://dx.doi.org/10.7867/1809-0354.2019v14n3p1069-1091}

Perguntamo-nos para onde ia a energia contida, reprimida nesses corpos, e sobre o que fazer para aliviar certas tensões. Nesse sentido, foram organizadas cinco (05) oficinas, com um total de 15 alunas. Por meio dessas oficinas, buscou-se reformular a Educação Física adaptada até então ofertada ao grupo, abrindo-a para a experimentação ao utilizar a dança e a expressão corpórea para estimular processos criativos. O objetivo do conjunto do trabalho foi movimentar as sensibilidades e as passionalidades que costumam se apresentar adormecidas e invisibilizadas nesse ambiente institucional.

Nesse contexto, este estudo quis colocar corpos e conceitos em movimento, no plano da cartografia, propor reflexões sobre a diferença e o CsO para fins de dar novas possibilidades de expressão através da arte da dança; libertar os enclausuramentos estéticos do gesto das normativas e pré determinações dadas e as linguagens da tradição nas quais se expressa o corpo feminino deficiente. No risco de aproximar conceitos vindos da Filosofia da Diferença dos corpos femininos deficientes, através de uma Educação Física adaptada, assumimos a possibilidade de construção de novas práticas capazes de incentivar a substituição das imposições estéticas da representação por performances e técnicas mais livres, que implicassem em experimentações.

Também rejeitamos um educar tradicional que se funda numa concepção de pensamento metafísico sob o qual um corpo fica subjugado às normas e aos pressupostos e juízos transcendentais; ao jugo do bom senso e de um senso comum fabricados para operar como avaliação que se sobredetermina com sua estética do belo e do bem e outras formas de beleza e bondade fabricadas. Lapoujade (2017, p.21) afirma que Gilles Deleuze e Félix Guattari produzem uma filosofia que é uma desconexão organizada ou um pensamento que inclui no processo do pensar o movimento aberrante. Tais considerações levam a afirmar que a imperfeição e o acaso passam a ser a forma do movimento que buscamos no andamento dessa cartografia.

A cartografia análoga ao rizoma (DELEUZE; GUATTARI, 1995) aponta para uma metodologia que quer trabalhar com a diferença, mantendo do diferente aquilo que nele é singular. Também nos aproximamos de autores ligados a essa concepção filosófica que operam com a arte e a dança, tais como: Machado (2009) e Gil (2001). Por fim, o que se pretende é a desconstrução de uma imagem do corpo feminino deficiente - na prática, 
Atos de Pesquisa em Educação - ISSN 1809-0354

Blumenau, v.14, n.3, p.1069-1091, set./dez. 2019

DOI: http://dx.doi.org/10.7867/1809-0354.2019v14n3p1069-1091

através da liberação dos movimentos afetivos que acionam outras potencialidades e possibilidades desses corpos; e na teoria, ao apontar para um corpo que se conceba sem imagem prévia ao movimento, que se deixe fluir como expressão de sentido e de entressentido, algo que o aproxima de um Corpo sem Órgãos.

No seu andamento, a cartografia preparou as oficinas e acompanhou a construção de modos de perceber e o que foi produzido no procedimento de proposição da arte da dança, já que essa metodologia pode ser interpretada como uma clínica de avaliação imanente (ZOURABCHVILI,2016). Cria-se uma cartografia quando se utiliza um modo de propor a multiplicidade e suas conexões, que também são múltiplas, quando nos vemos envolvidos com os elementos que a implicam. Esses elementos são trabalhados em uma filosofia da diferença que busca fugir à representação do ideal.

\section{PENSAR SEM IMAGEM - DIFERENÇA}

Para Deleuze (1988), o pensamento que vem da tradição envolve uma imagem dogmática, sobre a qual toda uma tradição afirma suas verdades. Essas verdades ou pressupostos se impõem à educação em geral e à educação dos corpos. Afinal, as concepções filosóficas dão base às disciplinas cujos fundamentos determinam a "verdade" ou a "falsidade" daquilo que as técnicas e as práticas corporais realizam no âmbito escolar. Interessa aqui entender que Deleuze nega uma relação entre linguagem e pensamento, na qual a primeira é o meio através do qual uma estrutura define o segundo. Antes dele, Nietzsche (1992), em o Nascimento da tragédia, já alertava para os perigos dessa relação, tanto para as concepções éticas como para as estéticas que delas derivam.

Os modos como a tradição que vem de Descartes, Kant, Hegel funda o pensamento crítico implicam em uma imagem do que é certo ou é errado, do que é feio ou bonito, do que é bom ou ruim. Tal imagem estrutura o pensamento de modo a que a vida se sujeite ao que está representado ou pressuposto, o que condiciona e antecipa a própria experiência. Deleuze (1988) preocupa-se em sua tese em derrubar tal imagem, quando mostra que ela é composta de oito postulados que deseja desconstruir, para liberar um pensamento sem imagem. 


\section{Atos de Pesquisa em Educação - ISSN 1809-0354 \\ Blumenau, v.14, n.3, p.1069-1091, set./dez. 2019 \\ DOI: http://dx.doi.org/10.7867/1809-0354.2019v14n3p1069-1091}

O primeiro postulado mostra que não se pode assegurar que haja no pensador uma boa natureza para o pensamento; o segundo, que nada ou que nenhuma verdade préexistente assegura que o ideal do senso comum nos leve ao bom senso; o terceiro, que nenhum pressuposto ou pensamento ulterior pode vir a garantir que as faculdades inerentes ao sujeito pensante o adequem ao objeto e façam dele o mesmo, no sentido de que possa ser pensado no pensamento; o quarto postulado diz que há uma ausência de clareza sobre a ideia na qual a diferença se apresenta como algo que deve ser subordinado ou reduzido a quatro elementos: o mesmo, o semelhante, o análogo e o oposto; o quinto trata da compreensão do próprio negativo e do erro no interior do pensamento, já que a tradição tende a antecipar tudo o que pode acontecer de mal no pensamento, sem dizer que esse mal seja entendido como derivativo de mecanismos externos; o sexto afirma que nada garante que a designação da função lógica ou da proposição possa ser tomada como lugar de verdade, pois quando aquilo que é designado toma o pensamento como lugar da verdade, está fundando previamente a ideia ou critério sobre o sentido; o sétimo diz das modalidades das soluções, como se o pensar pudesse ser reduzido a um modo de entendimento e não a vários; e o oitavo, por fim, diz do método como subordinação ao fim e ao resultado.

Com esses postulados Deleuze desconstrói o pensamento identitário de base idealista que está na origem da tradição filosófica desde Platão, e assegura à diferença um campo de expressão próprio; funda, portanto, a diferença. Tal ontologia da diferença permite novas concepções de corpo, de estética, de percepção de si, dos sentidos que atravessam e movimentam os corpos que estão na escola.

Mesmo reconhecendo a existência de muitos preconceitos que derivam dessa imagem de pensamento vinda da tradição - imagem que é hierárquica, seletiva e segregadora -, a instituição escolar na sua rotina do dia a dia costuma ignorar que o corpo é um campo e uma matéria afetiva. É preciso suspender um modo de se estar na escola enquanto corpo passivo no processo de ensino aprendizagem dos conteúdos, tanto teóricos como práticos.

Partindo da suspensão da recognição, o aprendizado estabiliza um tônus atencional singular que envolve a ativação de uma atenção aberta ao encontro de experiências 


\author{
Atos de Pesquisa em Educação - ISSN 1809-0354 \\ Blumenau, v.14, n.3, p.1069-1091, set./dez. 2019 \\ DOI: http://dx.doi.org/10.7867/1809-0354.2019v14n3p1069-1091
}

\begin{abstract}
pré-egóicas. Esta atenção se encontra até certo ponto desativada, sendo pouco investida na contemporaneidade. Aumentar sua potência e trabalhar para sua estabilização por intermédio de práticas de transformação de si é atualizar uma virtualidade por meio da aliança da surpresa com a regularidade. $\mathrm{O}$ aprendizado assume a forma de um círculo, em que o movimento é o de reincidir, retornar, renovar, reinventar, reiterar, recomeçar. [...] a lógica circular do aprender aponta para o problema do devir-mestre inacabamento do processo. $\mathrm{O}$ aprendizado jamais é concluído e sempre abre para um novo aprendizado. Ele é contínuo e permanente, não se fechando numa solução e não se totalizando em sua atualização, precisando por isso ser sempre reativado (KASTRUP, 2005, p.1279).
\end{abstract}

Limitado à normatização própria da estrutura educativa e a demandas concentradas de modo especial na Educação Física, o corpo encontra poucas oportunidades de expressar sua potencialidade. Trabalhar com a matéria corpórea e minimizar nela os efeitos das imposições das representações culturais e de gênero - efeitos que costumam acumular dúvidas, incertezas, imagens distorcias de si, do que é e do que pode ser - pode, assim, repercutir nas suas afecções e desejos.

Por isso resgatamos com Deleuze (1988) os oito postulados citados acima, que garantem que é possível um pensamento e uma filosofia da diferença - neste caso, operando como uma pré-filosofia que orienta outras ciências e artes do comportamento, como uma espécie de contrafundação da moral e da ética tradicionais. Portanto, é clara a necessidade de se buscar um pensamento sem imagens para lidar com certas questões que rondam a escola.

Foi visando um corpo intenso que nos utilizamos da Filosofia da Diferença e do conceito de $\mathrm{CsO}$ como elementos conceituais para organizar a experimentação de novas práticas corporais. A educação escolar, em geral ocupada em expandir a racionalidade, esquece o corpo no processo educativo; daí a busca de se resgatar os sentidos nas aulas de Educação Física. Contudo, essa disciplina implica em área que pode promover outras experiências corpóreas, que incluam sentidos e sensibilidade ou um corpo de sentido. Mas como educar um corpo do sentido se o sentido, como disse Deleuze (1974) em Lógica do sentido, é o que nos escapa o tempo todo?

O corpo é presença, gesto, linguagem e matéria ocupando, modificando e redefinindo o espaço, nos lugares individuais e institucionais subjetivados. Com que intensidade as gestualidades, os acenos, os maneirismos fazem movimentos nos espaços educativos e implicam em desejo calado, aquietado, reservado, controlado, sufocado. 
Atos de Pesquisa em Educação - ISSN 1809-0354

Blumenau, v.14, n.3, p.1069-1091, set./dez. 2019

DOI: http://dx.doi.org/10.7867/1809-0354.2019v14n3p1069-1091

Sendo o corpo linguagem, a performance, os modos de expressão da cultura o habitam e fazem dele símbolo, signo, significante e significado. No corpo se localizam o espaço, o tempo, a superfície e a borda; entendendo a borda aqui como um limite entre um corpo e outro, matéria que enquanto extensão é recorte, e enquanto indivíduo é intenção de estar no mundo. Para pensar um corpo do sentido é preciso abrir-se a um pensamento sem imagem, que o entenda como singular, diferente.

\section{CORPO SEM IMAGEM -INTENSO}

Artaud (1987) - e, antes dele, Nietzsche (1992) - chama atenção para o fato de que a base epistemológica da tradição acabou por reprimir nos corpos a expressão. $O$ envolvimento do corpo nos modos possíveis de pensá-lo não extrai dele as forças que o atravessam, os modos que o reduzem ao abstrato ou a imagem abstrata de sua materialidade. Denunciava Artaud que os corpos dissimulam a linguagem:

As palavras pouco falam ao espírito; a extensão e os objetos falam; as imagens novas falam, mesmo que feitas com palavras. Mas o espaço atroador de imagens, repleto de sons, também fala, se soubermos de vez em quando arrumar extensões suficientes de espaço mobiliadas de silêncio e imobilidade (ARTAUD, 1987, p.98).

Daniel Lins, desdobrando os estudos iniciados por Gilles Deleuze e Félix Guattari (1966, 1996), disse que CsO é um corpo sensível que se expande na percepção do mundo. Nessa acepção, é permitido vivenciar outros níveis de experiências, outras linguagens corpóreas; é mais que pele que experimenta e dialoga, músculos que se estendem e se contraem, transpiram: é movimento que evita enclausurar a emoção. Também fala de uma concepção na qual a matéria física que nos compõe reage à violência do estar no mundo.

Corpo composto de carne, sangue, músculos; que sofre, entre outros corpos, que deseja, atrai e expulsa estados emocionais com os quais interpreta e analisa o mundo. Corpo em seu estado de presença, no qual se expõe incoerências, aberrações e impossibilidades. Contudo, o cruel e o grotesco de O teatro da crueldade de Artaud (1987) são adjetivações desviadas em uma analogia, sensibilizadores de práticas educativas artísticas que fujam aos padrões da normalidade. A aproximação entre o absurdo e a arte 


\section{Atos de Pesquisa em Educação - ISSN 1809-0354 \\ Blumenau, v.14, n.3, p.1069-1091, set./dez. 2019 \\ DOI: http://dx.doi.org/10.7867/1809-0354.2019v14n3p1069-1091}

na linguagem artística permite que o sujeito se expresse exteriormente como protagonista dos antagonismos sob os quais estabelece seus sentimentos. O movimento e as forças que atravessam o vivido podem ser utilizados para transformar e reinventar a violência que subjaz aos processos da vida. Nesse momento, nos força a resgatar a Filosofia da Diferença e sua ontologia do movimento, uma vez que a lógica racional da tradição não dá conta de fundamentar o acontecimento "corpo sendo corpo".

Movimento que vital nos movimenta, oscilação com a qual experimentamos o mundo, os lugares e o tempo da vida; a relação com o espaço e com as possibilidades de se estar entre as coisas da natureza. As aulas de Educação Física adaptadas passaram a ser planejadas para exercitar, movimentar, fazer viver e experimentar novos modos de estar no próprio corpo que dança. Esses modos derivaram de práticas previamente selecionadas para serem, através do ritmo, produtoras de movimentos e sensações no corpo feminino deficiente.

Por tradição de um pensamento, aceitamos que o corpo físico seja objeto da Educação Física; já o pensar sobre o que pode o corpo ou sobre qual a matéria subjetiva que o compõe tem sido objeto da Filosofia desde muito tempo. Foi da reunião dessas duas áreas que surgiu a Filosofísica: um encontro fundado sobre a desconstrução de pressupostos vindos da tradição do pensar na Filosofia desde Platão. A proposta da Filosofísica é promover uma relação que revisa a concepção de um corpo-matéria, uma physis, operada pela Educação Física fundada na cultura ocidental, sobre um nous ou imagem transcendental de corpo e que, vinda dos conceitos filosóficos, impõe uma estética do bem e do belo (DELEUZE; GUATTARI, 1995). Por um lado, visa atualizar uma imagem de corpo biologizado e tecnicista e, por outro, a liberação de novas experiências sensório motoras. Por fim, nos utilizamos desse conceito, que ainda desejamos aprofundar em pesquisas futuras, para incentivar o despertar da coexistência entre corpo sensível e o corpo racional, propondo criar uma educação para um corpo extratemporal.

A Filosofísica é um forjar de experimentações em torno da aproximação entre a Educação Física e a ontologia de um pensamento filosófico da diferença, na tendência de apostar na educação de um corpo intenso e não extenso. Ela se coloca contra a imagem nascida no platonismo grego, difundida desde o helenismo e acolhida pelo narcisismo 


\section{Atos de Pesquisa em Educação - ISSN 1809-0354 \\ Blumenau, v.14, n.3, p.1069-1091, set./dez. 2019 \\ DOI: http://dx.doi.org/10.7867/1809-0354.2019v14n3p1069-1091}

ocidental cristão -imagem que conduz o corpo a se mostrar em respostas pouco produtivas às práticas de uma Educação Física voltada a rendimentos de uma forma física ideal. Essa concepção educativa que intitulamos Filosofísica trata da educação de um corpo sensibilia, sensível, desejante, "corpo povoado de intensidades" (DELEUZE; GUATTARI, 1996, p.13), extratemporal. Traz para as aulas o corpo do sentir-se, do perceber-se, do respirar e do explorar novas linguagens corpóreas; corpo que tem limite no começo, mas não necessariamente um fim.

Através da filosofisica, traz-se para reflexão um "deseducar" em relação a certa imagem de pensamento que condiciona o corpo feminino deficiente e o objetifica em corpo imóvel, amorfo, invisível, incapaz de conviver satisfatoriamente com seus sentimentos. Disse Schöpke (2017, p.291) que o "CsO diz respeito à reinvenção da própria vida, diz respeito à produção da singularidade, a produção de si mesmo".

Retomando o corpo do desejo (DELEUZE; GUATTARI, 1966, 1996) que é leve, rítmico e fluido, e propondo que dance uma técnica denominada Dança Contato Improvisação, convida-se à libertação dos movimentos de um corpo feminino deficiente, incita-se a soltar as emoções que se rarefazem nas formas duras que as aprisionam. Corpo em dança que libera o incorporal, que atravessa os conceitos da Filosofia, da arte, da Educação Física, cujas multiplicidades contextualizam e o desdobram no cenário escolar.

O corpo feminino deficiente, como já se disse, é sujeito à normatização e à representação estética impostas por uma imagem plástica, produto e produção de um modelo de beleza elaborado pelos aparelhos de Estado e pelas máquinas de captura. Estas promovem uma educação forjada na máquina abstrata que as fabrica (DELEUZE; GUATTARI, 1996).

A experiência e o convívio com as estudantes com deficiência suscitaram questões relacionadas ao sentido do que se faz e ao que se pode propor que faça sentido, quando o que está em ressalva é um campo sensível. E fez surgir a vontade de fazer algo diferente. As sujeitas com deficiência são meninas e mulheres em outros modos de ser. "Toda educação cuida de quem educa, quando cuida do sentido para o qual educa! O que envolve educador e educando como parte indissociáveis do mesmo processo. Logo, educar é cuidar do sentido?"(CUNHA, 2011, p.170).Passou a fazer cada vez mais sentido a necessidade 
Atos de Pesquisa em Educação - ISSN 1809-0354

Blumenau, v.14, n.3, p.1069-1091, set./dez. 2019

DOI: http://dx.doi.org/10.7867/1809-0354.2019v14n3p1069-1091

de sensibilizar um corpo feminino deficiente, que, reconhecido sensível, pede uma ação adequada.

Em meio a esses corpos com suas potencialidades estéticas, afetivas e emocionais, surgiram inúmeros questionamentos e, ao mesmo tempo, múltiplas alternativas sobre o que era plausível fazer em uma aula de Educação Física adaptada. Criar as oficinas e pensar sobre a proposta provocou reflexões sobre os conteúdos adquiridos durante a formação acadêmica e profissional. Operar com a diferença movimenta o pensar e o agir, significa estar aberta e sensível aos acontecimentos advindos da experiência. Propor a dança foi uma alternativa para que houvesse toque, vibração entre corpos, percepção de si. E a dança, com sua técnica do improviso, pareceu libertadora.

A busca de ocupar e mobilizar através das práticas educativas um outro corpo - e aqui voltamos a parafrasear Gil (2001) -, delimitando que "o espaço do corpo é o corpo tornado espaço", se colocou como desafio. O corpo como imagem que habita um espaço ou composição estética não é produzido pelos desportistas e artistas que o utilizam. Conforme o autor, o corpo nasce do investimento afectivo. Nessa perspectiva, se fez dançar a imagem/imaginação do corpo feminino deficiente na busca de um corpo da diferença, corpoutramentos que despertam pela sensibilização de novos (re) conhecimentos de si, tal máquinas desejantes que se opõem ao Édipo (DELEUZE; GUATTARI,1966, p.409).

Esse processo reconduz a pensar como um pensamento sem imagem pode ser buscado e desdobrado em corpoutramentos, em gesto e sentido de um corpo sem imagem (GIL,2001; DELEUZE; GUATTARI, 1996). Desestratificar, nessa ausência de modelo, a composição de uma imagem dogmática que atrai concepções vindas dos estratos da cultura e dos seus âmbitos sociais, políticos, científicos e religiosos. Na perspectiva de ativar um CsO, nossa proposta se aliou à técnica da Dança Contato Improvisação e fez desta um veículo para sensibilizar perspectivas apáticas.

\section{OFICINAS DE DANÇA CONTATO IMPROVISAÇÃO}

Escolhida como estratégia para movimentar os corpos das meninas e mulheres sujeitas da nossa pesquisa, a Dança Contato Improvisação teve como precursores Steve 
Paxton (apudSILVA, 2014) e outros bailarinos ${ }^{1}$ da década de 1970 que trabalharam com novas percepções e experimentações do movimento e da própria dança. De acordo com Silva (2014), os primeiros encontros relacionados à prática ocorreram no Rio de Janeiro, em 1988. A dança, cujo estilo é bastante peculiar, pode envolver duas ou mais pessoas, que juntas improvisam movimentos livres. $O$ ato de dançar, assim como a performance e a coreografia, surge de modo quase totalmente espontâneo, no contato entre os participantes. Torna livre a expressão do movimento e a improvisação das escolhas, libera emoções e instintos a cada toque entre os corpos.

Nas oficinas realizadas, a prática da Dança Contato Improvisação atualizou ou ativou as afetividades produzidas pelos corpos envolvidos - que, para além de serem reduzidas a negativas, são geralmente entendidas como abusivas, abjetas e perversas. Esses corpos, assim como os de outros atores do espaço escolar, foram convidados a conviver, e não a corrigir suas imperfeições. Propôs-se, assim, uma mudança no processo educativo, de modo geral dirigido por uma imagem dogmática de pensamento, ou seja, uma forma cristalizada de pensar que é pré-existente, é contra o novo, ao ainda inexistente, e fundada em pressupostos que impedem o acontecimento e levam a julgar a experiência, ao invés de aprender com ela.

O corpo que em sua presença e nas questões que traz ao entendimento através de seus movimentos é corpo-educação, inquieta e questiona o que se faz e o sentido das práticas organizadas para fins educativos. Esse corpo ocupa uma sala de aula, tomando seu lugar de superfície, imagens, aparências, presença, performances, simulações, de prática e de política em uma vida coletiva. Desdobrar esse corpo numa espécie de corpoutramentos, em oficinas de dança e expressão corporal, traz possibilidades para novas imagens de si, ativando conceitos como: pensamento sem imagem; percepção; afeç̧ão; Corpo sem Órgãos, todos retirados da Filosofia da Diferença de Gilles Deleuze (DELEUZE, 1974; DELEUZE; GUATARRI,1996).

\footnotetext{
${ }^{1}$ No início, houve a colaboração dos (as) bailarinos (as) Nancy Stark Smith, Nita Little, Daniel Lepkoff, Alito Alessi, entre outros.
} 


\section{Atos de Pesquisa em Educação - ISSN 1809-0354 \\ Blumenau, v.14, n.3, p.1069-1091, set./dez. 2019 \\ DOI: http://dx.doi.org/10.7867/1809-0354.2019v14n3p1069-1091}

A Dança Contato Improvisação ${ }^{2}$ foi usada não apenas como instrumento didático e de prática corporal. Pretendeu-se também utilizá-la para movimentar imagens de si, de maneira a romper com determinações estéticas. Por meio do toque, do contato de um corpo feminino com outras feminilidades corpóreas, se quis sensibilizar para a percepção do gênero como construção simbólica e cultural do coletivo; pela improvisação, intencionouse fazer dançar outro algo que é o acontecimento, do improviso, do movimento imperfeito, da deficiência.

IMAGEM 1: FOTOGRAFIA 1:

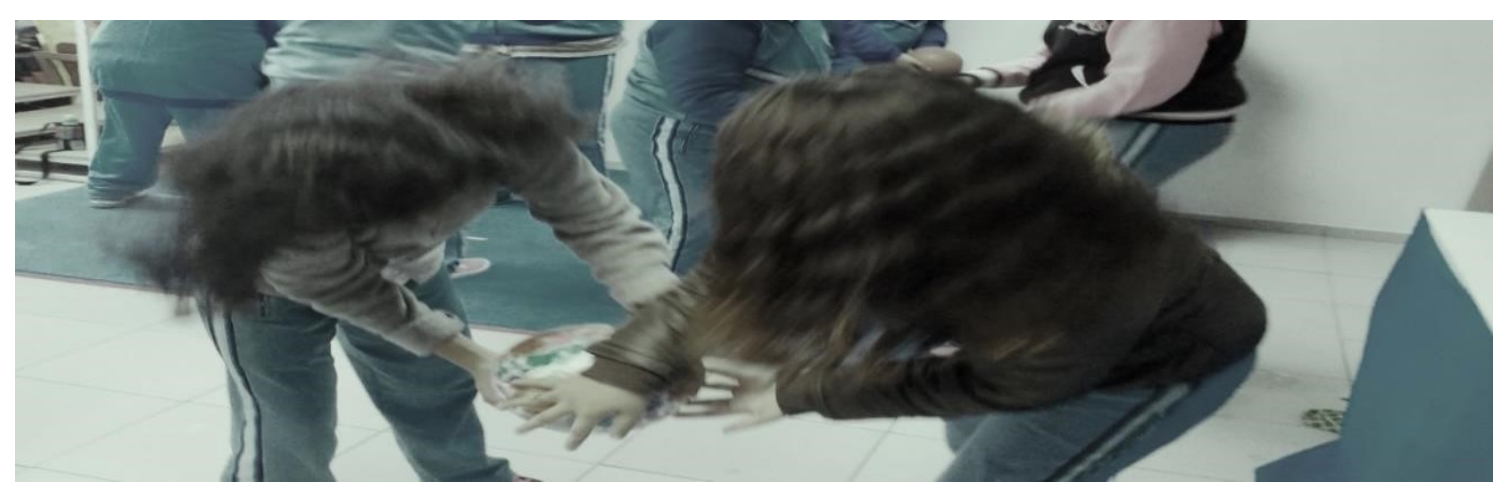

FONTE: RODRIGUES, 2016, p. 72

LEGENDA: Práticas de experimentações de Contato e Improvisação

As oficinas propunham vivenciar a música e o ritmo, partindo deum aquecimento ou alongamento corporal que aos poucos libera os movimentos iniciais. Periodicamente, a música mudava e as práticas de expressão corporal iam se incrementando, de forma livre, em duplas ou em grupos. As oficinas finais promoveram práticas de contato improvisação e diferentes possibilidades de dançar com o outro, ora improvisando, ora retomando o

\footnotetext{
${ }^{2}$ Este ensaio resulta de uma investigação (Cf. RODRIGUES, M.C. Cartografias do sensível: o corpo deficiente feminino nas aulas de Educação Física, 2016) desenvolvida no segundo semestre do ano de 2016, em uma Escola de Educação Especial, APAE da cidade de Curitiba, no Paraná. Tal estudo, realizado no âmbito do Mestrado Profissional: Teoria e Prática de Ensino, PPGE -Edu/UFPR, se deu durante cinco quintas-feiras, no período da tarde. As oficinas da Dança Contato Improvisação foram filmadas e fotografadas por uma profissional contratada que acompanhou as oficinas ao longo de um mês e meio. A proposta do trabalho foi apresentada e discutida com os responsáveis pelas estudantes, que assinaram o Termo de Consentimento Livre (TCL) autorizando a participação. O grupo era composto por 15 alunas com diferentes deficiências intelectuais e físicas leves, todas com idade igual ou superior a 18 anos. Todo o processo passou pelo comitê de ética da Universidade Federal do Paraná e foi previamente aprovado.
} 


\section{Atos de Pesquisa em Educação - ISSN 1809-0354 \\ Blumenau, v.14, n.3, p.1069-1091, set./dez. 2019 \\ DOI: http://dx.doi.org/10.7867/1809-0354.2019v14n3p1069-1091}

contato que se rompia. Assim, buscou-se extrair dos corpos novas vibrações, energias, sensações que permitissem fazer fluir o diferente para potencializar corpoutramentos, fugindo das amarras dos organismos da significância e da subjetivação (DELEUZE;GUATTARI, 1996).

Essa modalidade de dança e sua inestética, ou antiestética, foi compreendida e acionada na construção de um corpo feminino deficiente sensível e sem órgãos. A necessidade de manutenção do toque em movimento permitiu a experimentação de uma potência nova dos corpos, sem atá-los à representatividade de gênero. Alcançar um movimento em conjunto, no encontro, desencontro e dissolução dos corpos, em alguns momentos, evoca corpoutramentos, o que não consiste em fundir identidades, mas em pensar ou experimentar o corpo sem imagem, sem limites, que se esquece das representações sociais para poder reinventá-las e sobreviver a elas, acionando campos de forças ativas em oposição às forças reativas que tendem a imobilizá-lo e fazem da deficiência elemento limitador das capacidades e possibilidades do corpo feminino deficiente, tratadas de forma pejorativa. Através da dança, produz-se linhas de fugas aos conceitos engessados e limitados a respeito desse corpo e rompe-se as linhas duras que o negligenciam.

O dançar improvisado não consistiu em dar ou forjar sentidos, significados, conceitos aos movimentos, nem em reter uma interpretação ou linguagem. Apenas explorou, no toque de corpo com corpo, uma aproximação de si mesmo; experimentou gestos, deixando que a energia que movia o corpo naquele segundo, minuto ou hora se concretizasse em forma de dança. Nesse sentindo, os corpos femininos deficientes falaram verdadeiramente na dança. Gil (2001) conduz a pensar que:

A dança constrói o plano de movimento onde "o espirito e o corpo são um só" porque o movimento do sentido desposa o próprio sentido do movimento: dançar é não "significar", "simbolizar" ou "indicar" significações ou coisas, mas traçar o movimento graças ao qual todos estes sentidos nascem. No movimento dançado o sentido torna-se acção. (GIL, 2001, p. 95).

Assim, o ato de dançar produz sentidos, encontros e desencontros de fluxos energéticos nos corpos. Os movimentos são desencadeados por afetos e, por isso, não podem ser interpretados ou definidos, tendo em vista que se configuram na expressão de 


\section{Atos de Pesquisa em Educação - ISSN 1809-0354 \\ Blumenau, v.14, n.3, p.1069-1091, set./dez. 2019 \\ DOI: http://dx.doi.org/10.7867/1809-0354.2019v14n3p1069-1091}

fluxo energético de uma pessoa. Durante a ação de dançar sob a técnica do contato improvisação, foi possível proporcionar uma consciência de si mesmo e sua relação com o mundo. Como disse Gil (2001), fizemos do dançar inconscientemente o consciente, sem que a consciência determinasse os movimentos, sem investir na busca da perfeição ou dispensar atenção intensa a uma parte do corpo e/ou órgão. A intenção era libertar a máquina abstrata, sem que isso represente

[...] intensificar os poderes da consciência de si, da própria imagem, do próprio corpo visto do interior como um objeto exposto, por um lado; e por outro, não abolir esses poderes ao ponto de deixar o corpo agir às cegas. A consciência de si deve deixar de ver o corpo do exterior, e tornar-se uma consciência do corpo. [...] O relaxamento da atenção exterior, que se aplica a certo órgão como a um objeto, decorre naturalmente do movimento dançado. (GIL, 2001, p. 159).

Fazer fluir o corpo feminino deficiente com a Dança Contato Improvisação pretende tornar possível um corpo-expressão, corpo-rizoma, corpo-sentido, na expectativa de romper com a imagem do pensamento dogmático e sua lógica abstrata que impõe um corpo-organizado e propor uma lógica do sentido intencionando um corpo sensível. O sentido aqui tratado "é o exprimível, ou o expresso da proposição e o atributo do estado das coisas" (DELEUZE, 1974, p. 23).

Como olhar para tudo isso que vinha acontecendo? Era necessário organizar minimamente os elementos obtidos, que a princípio dividem nossa atenção, como observa Kastrup:

A entrada do aprendiz de cartógrafo no campo da pesquisa coloca imediatamente a questão de onde pousar sua atenção. Em geral ele se pergunta como selecionar o elemento ao qual prestar atenção, dentre aqueles múltiplos e variados que the atingem os sentidos e o pensamento (KASTRUP, 2009 p.35).

Colocar-se como aprendiz em uma pesquisa cartográfica envolve prestar atenção em tudo que compõe os momentos experimentais: o uso do chão, os corpos agachados, as pontas dos pés, os olhos fechados, os órgãos esquecidos na intervenção de um em outro. Corpo tocando corpo, dançando corpo, em dois, em três, em mais; o grande grupo se esforçando para manter-se grupo no contato instigou a criação e a conexão. Ao fim de cada oficina era realizada uma síntese conectiva (roda de conversa), durante a qual eram 


\section{Atos de Pesquisa em Educação - ISSN 1809-0354 \\ Blumenau, v.14, n.3, p.1069-1091, set./dez. 2019 \\ DOI: http://dx.doi.org/10.7867/1809-0354.2019v14n3p1069-1091}

compartilhadas as sensações, impressões, desejos, dificuldades e opiniões das meninas quanto à prática, expressando como se perceberam entre corpos durante a dança.

Selecionamos alguns registros dos relatos feitos pelas participantes durante as rodas de conversa e que remetem aoscorpoutramentos por vir:

“-É muito difícil! Esta dança é difícil!

-Deu calor!

- Eu gostei da dança, só achei este de dançar em três mais difícil.

- Achei difícil porque tem que encostar uma na outra e dançar.

- Me senti mais alegre, mais aliviada, mais animada!

- Esquece dos problemas!

- Se soltamos mais(sic)."

Nas narrativas das meninas deficientes que participaram das oficinas é possível detectar a necessidade de um trabalho contínuo com os corpos deficientes, para fugir à ideia de tratá-los de modo depreciativo. A prática quis favorecer o distanciamento em relação às normativas instauradas, permitindo, por meio da escolha do movimento que toca o que se movimenta, o acesso ao limiar da expressão (DELEUZE, 1974).Buscou-se a forma fluída pelo ritmo, deformada em outras formas possíveis, toques entre toques que vêm deum outro corpo, desdobrados em corpoutramentos. Foram atividades práticas que almejaram expandir as emoções represadas e estimular a sensualidade, a gestualidade e experimentações dos sentidos, ao invés de capturá-las. Incentivar o toque, tocar o estranho e o extremo que implica a superfície do corpo e da pele do outro, um limite possível, passível, para conhecer-se a si próprio. Nesse jogo da expressão há um "dentro" e um "fora" que compõem o gesto corpóreo e a corporeidade.

Durante as oficinas, sugerimos mais sentir do que pensar o corpo diferente, movimentando-o e inspirando a flexibilizar sentidos de ser, convocando-os a se expressarem de outra maneira, corporalmente. A Dança Contato Improvisação propiciou a atualização de uma imagem corpo/feminino/deficiente, imagem que, no entanto, não é totalmente dissociada da representação de uma plástica capitalista, da máscara que essa estética impõe, quando separa os "bons" e os "maus", os "belos" e os "feios", "os perfeitos" e os "imperfeitos", os que estão "em forma" e os "deformados".

\footnotetext{
${ }^{3}$ Falas das participantes das oficinas de Contato Improvisação, na escola de Educação Especial.
} 
Atos de Pesquisa em Educação - ISSN 1809-0354

Blumenau, v.14, n.3, p.1069-1091, set./dez. 2019

DOI: http://dx.doi.org/10.7867/1809-0354.2019v14n3p1069-1091

IMAGEM 2: FOTOGRAFIA 2

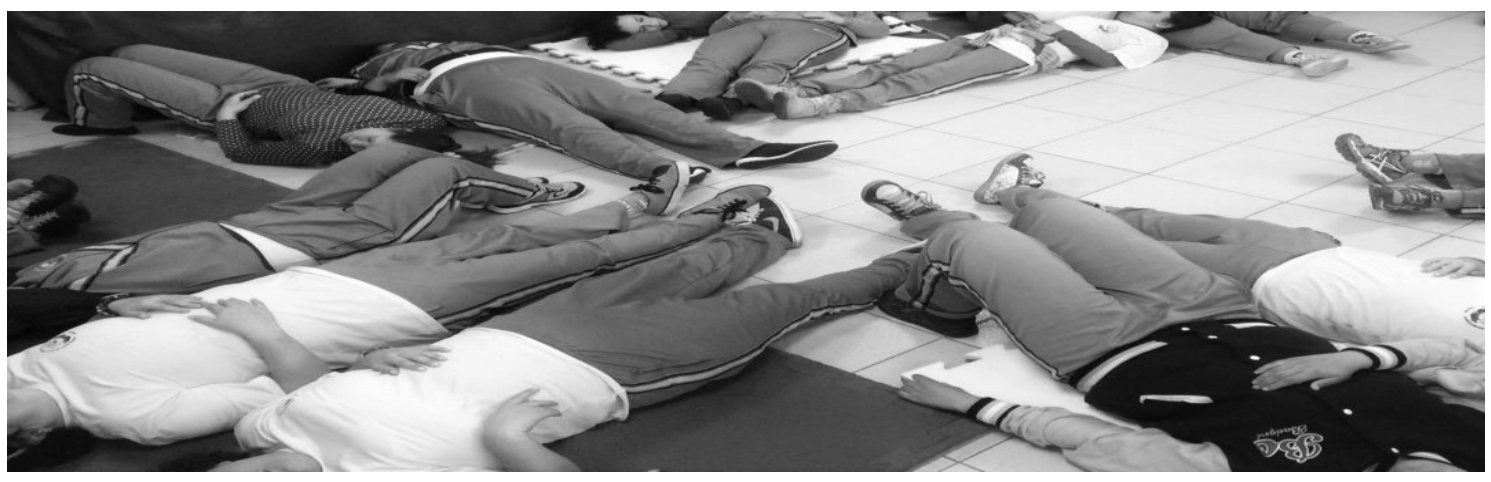

FONTE: RODRIGUES, 2016, p. 72

LEGENDA: Práticas de experimentações de Contato e Improvisação no solo

Em nenhum momento - antes, durante ou depois das atividades que fizeram dançar o corpo feminino deficiente - pretendeu-se estratificá-lo, nem agrupar ou aproximar determinações que envolvessem esse composto subjetivo; tampouco se quis referir-se a ele de maneira a reduzi-lo a esses elementos. Tal uma hecceidade, ao reunira Dança Contato Improvisação e o corpo feminino deficiente, o que se almejou foi um novo arranjo das multiplicidades e, com ele, novas sensações de si. As hecceidades permitem compreender que há sempre um "algo a mais", que convoca outro "algo a mais", e assim por diante. Daí a Filosofia da Diferença de Gilles Deleuze e Félix Guattari (1996) também ser chamada de Filosofia das Conexões. Como disse Galo, é um pensar em que

[...]Cada conceito remete a outro conceito, a outro problema. Cada conceito conecta-se com vários outros e pede novas conexões. Assim, num movimento infinito do pensamento, o que temos são sempre novos conceitos sendo criados, por conexão, por deslizamento, por deslocamento... e a invenção de novos problemas, como num moto contínuo (GALLO, 2008, p. 66).

Ao fundamentar as práticas desenvolvidas para fins de perceber o corpo deficiente feminino, esse pensamento permite, ou ousa, outra compreensão, afirma possibilidades além das determinações e sedimentações que nosimpõem formas, funções, ligações, organizações determinantes e hierarquizadas, transcendências organizadas para extrair 


\section{Atos de Pesquisa em Educação - ISSN 1809-0354 \\ Blumenau, v.14, n.3, p.1069-1091, set./dez. 2019 \\ DOI: http://dx.doi.org/10.7867/1809-0354.2019v14n3p1069-1091}

trabalho útil (DELEUZE; GUATTARI,1996).Torna, enfim, possível que essas determinações sejam postas em suspensão, ao menos temporariamente.

A tentativa de aproximar o Corpo sem Órgãos do corpo feminino deficiente revela certos aspectos relevantes que envolvem tal conceito. Primeiramente, o CsO não se refere a um conceito limitado, engessado, inflexível, mas sim a um conjunto de práticas constantes. O alcance de um $\mathrm{CsO}$, não é de modo algum linear, metódico, com início, meio e fim. Não há um ponto de chegada, conforme afirmação de Deleuze e Guattari (1996, p. 9): "Ao Corpo sem Órgãos não se chega, não se pode chegar, nunca se acaba de chegar a ele $[\ldots]$.

Trata-se de estar em constante devir, de novas e infinitas possibilidades de ser, fazer, sentir, existir. Permitir ao corpo sentidos e sensibilidades singulares, distanciando-o de determinações sociais, significações, de interpretações e identidades rígidas e revelando o corpo-plural, em resistência ao corpo-uno. Como afirma Deleuze a respeito da corporeidade múltipla:

[...]unificações, subjetivações, racionalizações e centralizações não têm qualquer privilégio, sendo frequentemente impasses ou clausuras que impedem 0 crescimento da multiplicidade, o prolongamento e o desenvolvimento de suas linhas, a produção do novo (DELEUZE, 2013, p. 187).

Retomando Artaud (1987), esse corpo sensível que expande o sentimento declara guerra aos órgãos/organismo. A proposta das oficinas foi justamente romper a funcionalidade de um corpo com órgãos, metódico, funcional, estratificado, produtivo, em busca da promoção de linhas de fugas para um corpo mais experimental e intensivo, aberto ou expandido aos devires. Ir além das significações e determinações morais, estéticas, religiosas, midiáticas evoca a desterritorialização de um território repleto de linhas duras que limitam a experimentação, os sentidos e desejos, o corpo.

O diálogo da dança com o corpo feminino deficiente permitiu ativar uma imanência adormecida, quando inimizou binarismos instaurados socialmente, através dos quais muitas das expressões corpóreas ficam capturadas.

Por fim, tentou-se descrever uma realidade ou um acontecimento socioeducativo que produziu efeitos em todas as pessoas que dele participaram, especialmente para a 


\section{Atos de Pesquisa em Educação - ISSN 1809-0354 \\ Blumenau, v.14, n.3, p.1069-1091, set./dez. 2019 \\ DOI: http://dx.doi.org/10.7867/1809-0354.2019v14n3p1069-1091}

educadora responsável pelas meninas, que é especialista em educação especial, e para as sujeitas da pesquisa, estudantes com deficiência.

As linhas dessa cartografia tramaram percepções em várias direções. Do ponto de vista das cartógrafas, foi um processo de aquisição de conhecimento, aberto a transformações que implicaram em movimentos subjetivos e objetivos. Podem ser percebidos como subjetivos os seguintes movimentos: i) houve o deslocamento dos saberes do educador ao perceber seu "não sabido"; ii) algo singular se deu ao perceber-se como "um outro de si" no que ainda não dominava; iii) a clínica se fez no sentir o desconforto da educadora com os corpos das estudantes, no pensar a concepção de corpo que de modo instrumental costumava utilizar ao conceber suas aulas.

Como movimentos objetivos, destacamos: iv) houve a necessidade de buscar/criar uma abordagem extra sala de aula; iv) uma dança e uma técnica de sensibilização diferente foram ativadas; v) algo precisou ser aprendido e possibilitou uma atualização profissional espontânea; vi) por fim, o registro das apresentações trouxe a necessidade de procurar conceitos que pudessem fundar esse campo do sensivel para fins de registrar esse acontecimento.

Fazendo uso da metodologia cartográfica proposta por Deleuze e Guattari (1995), do conceito de CsO $(1966 ; 1996)$ proposto pelos mesmos autores e da Filosofia da Diferença e do pensamento sem imagem, entre outros conceitos de Deleuze (1988), a pesquisa quis criar oficinas para acompanhar o movimento em desenvolvimento de liberação de fluxos desejantes dos corpos femininos deficientes. Todo o processo teve registro fotográfico cuidadoso, minimamente interventivo, buscando expressões espontâneas ou dirigidas pela dança, para fins de colher dados. As oficinas também foram gravadas e as narrativas das meninas, digitalizadas.

\section{CONSIDERAÇÕES FINAIS}

O corpo, por sua condição subjetiva e objetiva, é uma imagem que se pode analisar por múltiplos pontos de vista, provocando infindáveis reflexões. Como forma, expressão física, o corpo pode ser reconstruído, redesenhado, reformulado constantemente. Por outro 


\section{Atos de Pesquisa em Educação - ISSN 1809-0354 \\ Blumenau, v.14, n.3, p.1069-1091, set./dez. 2019 \\ DOI: http://dx.doi.org/10.7867/1809-0354.2019v14n3p1069-1091}

lado, as imagens que compõem os pensamentos sobre o corpo estão carregadas de representações e plásticas socioculturais, produzindo concepções cuja origem funcionalista e finalidade estética precisam também ser reconstruídas e repensadas. São pressupostos que se impõem e pré-determinam as experiências. Defendemos que o corpo não se reduz aos mapas corporais construídos atualmente, que não fogem à padronização como forma de controle. Corpo reproduzido, criptografado e definido por números, códigos e símbolos, formas que homogenizam e uniformizam as diferenças, aniquilando ou reduzindo a subjetividade.

Os resultados obtidos a partir da coleta dos relatos das participantes desta pesquisa nos permitem perceber, no conjunto da proposta, elementos que fazem parte da cartografia ou compõem o rizoma. Seus movimentos e seus relatos mostram certa produção de sentimentos singulares. O movimento dos corpos na Dança Contato Improvisação, ao mesmo tempo ritmado e ao acaso, permitiu a liberação de possíveis devires, nos momentos em que as sensações inesperadas se deram; a dança abarcou uma consciência da realidade de fina clínica do acaso no acolhimento da existência concreta e singular do corpo entre corpos; houve hecceidades, conjunções e operações individuais e impessoais, ao mesmo tempo intensivas e sem sujeito. Por fim, a dança permitiu um grupo desigual em cena.

A experimentação dos espaços tempos livres ou o estar em movimento indefinido dos corpos femininos deficientes de algum modo pertenceu ao acontecimento ou experiência que subverte a lógica moderna (do desenvolvimento sócio cognitivo, por exemplo). Pode-se dizer que o rizoma ou o processo cartográfico foi exercitado, no sentido de que a prática se organizou sem contar com conteúdos centrados. A ideia da sequência das oficinas foi observar zonas de intensidade, territórios em composição e decomposição atravessados por graus de territorialização, desterritorialização de sentimentos e afetos corpóreos (DELEUZE; GUATTARI, 1995).

$\mathrm{Na}$ busca de um corpo mais intensivo, em oposição a um corpo extensivo, essa cartografia convocou outra imagem subjetiva e objetiva para a Educação Física - uma Filosofísica, junção da Filosofia da Diferença com a Educação Física. Quis um educar no qualo corpo é lugar do sensível, expressando-o como um acontecimento estético, na busca 
Atos de Pesquisa em Educação - ISSN 1809-0354

Blumenau, v.14, n.3, p.1069-1091, set./dez. 2019

DOI: http://dx.doi.org/10.7867/1809-0354.2019v14n3p1069-1091

ética da construção de si, de corpoutramentos. Corpo cujo sentido de si é atravessado por outros corpos e imagens que o constrangem ou expandem. Corpo do sentido que está sempre em movimento de construção e desconstrução de um gesto de si. Afinal, como disse Deleuze, interpretando Klossowski, corpo que "é capaz de gestos que dão a entender o contrário daquilo que indicam." (DELEUZE, 1974, p.289).

\section{CLAUDIA MADRUGA CUNHA}

Doutora em Educação. Pós-Doutora em Educação pela Universidade do Porto (UP/Portugal). Atua no Setor de Educação Profissional e Tecnológica/SEPT e nos programas de Pós-Graduação em Educação, Mestrado e Doutorado em Educação/PPGEEdu e no Programa de Mestrado Profissional: Teoria e Prática de Ensino/PPGE:Mp da Universidade Federal do Paraná- UFPR.

\section{MICHELE CAROLINE DA SILVA RODRIGUES}

Mestre em Educação pela Universidade Federal do Paraná - UFPR. Especialista em Educação Física Adaptada.

\section{REFERÊNCIAS}

ARTAUD, A.O teatro e seu duplo. São Paulo: Martins Fontes, 1987.

ARTAUD, A.O teatro da crueldade. In:ARTAUD, A.O teatro e seu duplo. São Paulo: Martins Fontes, 1987.

CHAGAS, E.P. Corpo feminino do detalhe.... Uma possibilidade de construção de novos territórios para a subjetividade feminina. In: ROMERO, E. Corpo, mulher e sociedade. Campinas, SP: Papirus, 1995.

CUNHA, C.M. Filosofia Rizoma: Metamorfoses do pensar. Curitiba: CRV, 2011.

DELEUZE, G. Lógica do sentido. Tradução deL. R.Salinas. São Paulo: Perspectiva, 1974.

DELEUZE, G. Nietzsche. Tradução de A. Campos. Lisboa: Edições 70, 1976.

DELEUZE, G. Nietzsche y la filosofia. Tradução de C. Artal. Barcelona: Anagrama, 1986.

DELEUZE, G. Diferença e repetição. Tradução de L. Orlandi e M. Machado. Rio de Janeiro: Graal, 1988. 
Atos de Pesquisa em Educação - ISSN 1809-0354

Blumenau, v.14, n.3, p.1069-1091, set./dez. 2019

DOI: http://dx.doi.org/10.7867/1809-0354.2019v14n3p1069-1091

DELEUZE, G.Conversações.3. ed. Tradução de P. P. Pelbart. São Paulo: Editora 34, 2013.

DELEUZE, G.; GUATTARI, F. O anti-Édipo: capitalismo e esquizofrenia. Tradução de J. M. Varela e M. Carrilo. Lisboa: Assírio \& Alvim, 1966.

DELEUZE, G.; GUATTARI, F. O que é a filosofia? Tradução de B. Prado JR. e A. A. Muños. Rio de Janeiro: Editora 34,1992.

DELEUZE, G.; GUATTARI, F. Mil platôs 1: capitalismo e esquizofrenia. Tradução de A. Guerra Neto e C. P. Costa. Rio de Janeiro: Editora 34, 1995.

DELEUZE, G.; GUATTARI, F. Mil platôs 3: capitalismo e esquizofrenia. Tradução de A. Guerra Neto, A. L. de Oliveira, L. C. Leão e S. Rolnik. Rio de Janeiro: Editora 34, 1996, v.3.

GALLO, S. Deleuze \& Educação. Belo Horizonte: Autêntica, 2008.

GIL, J. Movimento total: o corpo e a dança. Lisboa: Relógio d’Água, 2001.

KASTRUP, V. Políticas cognitivas na formação do professor e o problema do devirmestre. Educação e Sociedade. Campinas, v. 26, n. 93, dez. 2005, p. 1273-1288.

Disponível em:

https://social.stoa.usp.br/articles/0015/3774/Formacao_do_Professor_e_Devir-Mestre.pdf. Acesso em: 10 mar. 2019.

KASTRUP, V. O funcionamento da atenção no trabalho do cartógrafo. In: KASTRUP, V.; PASSOS, E.; ESCÓSSIA, L. da (orgs.). Pistas do método da cartografia: pesquisa intervenção e produção de subjetividade. Porto Alegre: Sulina, 2009.

LAUPOUJADE, D. Deleuze, os movimentos aberrantes. Tradução de L. G. dos Santos. São Paulo: n-1, 2017.

LINS, D. Antonin Artaud: o artesão do corpo sem órgãos. Rio de Janeiro: RelumeDumará, 1999.

MACHADO, R. Deleuze, a arte e a filosofia. Rio de Janeiro: Zahar, 2009.

NIETZSCHE, F. O nascimento da tragédia ou helenismo e pessimismo. Tradução de J. Guinsburg. São Paulo: Companhia das Letras, 1992.

RODRIGUES, M.C. Cartografias do sensível: o corpo deficiente feminino nas aulas de Educação Física.2016. Dissertação (Mestrado Profissional em Teoria e Prática de Ensino) - Setor de Educação, Universidade Federal do Paraná, Curitiba, 2016. 
Atos de Pesquisa em Educação - ISSN 1809-0354

Blumenau, v.14, n.3, p.1069-1091, set./dez. 2019

DOI: http://dx.doi.org/10.7867/1809-0354.2019v14n3p1069-1091

ROLNIK, S. Cartografia sentimental. Porto Alegre: Sulina, 2007

SCHÖPKE, R. Corpo sem órgãos e a produção da singularidade: a construção da máquina de guerra nômade. Rev. Filos., Aurora,Curitiba, v. 29, n. 46, p. 285-305, jan./abr. 2017. Disponível em: https://periodicos.pucpr.br/index.php/aurora/article/view/5697 Acesso em: 10 mai. 2019

SILVA, H. L. Desabituação compartilhada. Valença: Selo A Editora, 2014.

ZOURABICHVILI, F. Deleuze uma filosofia do acontecimento. São Paulo: Editora 34, 2016. 